\title{
THE EFFECT OF INNER DIAPHRAGMS AND NON-CONTINUOUS SILL SECTION ON THE STIFFNESS OF AUTOMOTIVE B-PILLAR
}

\author{
C.F. Tan*, S.A. Shamsuddin \\ Department of Design \& Innovation, Faculty of Mechanical Engineering, \\ Kolej Universiti Teknikal Kebangsaan Malaysia, \\ 75450 Ayer Keroh, Malacca, Malaysia
}

M.H. Shafie

Fourth Malaysian Infantry Division Headquarters Royal Electrical and Mechanical Corps

Ministry of Defence, Malaysia

Wardieburn Camp, Kuala Lumpur, Malaysia

Received 05 December 2005

\begin{abstract}
The paper discusses the knowledge on the behaviour of T-frame under specific loading will be obtained by experimental methods in order to investigate the deflection of the vehicle B-pillar or $\mathrm{T}$-frame. In addition, a series of $\mathrm{T}$-frame were designed with inner diaphragm at various location in the sill member in order to investigate the effect of inner diaphragm and noncontinuous closed hat section in the sill member. Lastly, the results from the experimental tests were compared with the finite element analsysis results to demonstrate the effectiveness of the inner diaphragm in the automotive B-pillar.
\end{abstract}

Keywords: vehicle T-frame, inner diaphragm, non-continuous closed hat section, experimental methods, finite element analysis

\section{INTRODUCTION}

The framework of the automotive body structure is comprised of thin walled section members in the formed of overlapping sheet metal fastened by spot-welds. In analyzing the structure of the vehicle body, it is assumed that the intersecting angles at which member are joined together, varies according to the external forces. The automotive frame joints are subject to dynamic and static loads. The dynamic analysis can be carried out using matrix methods provided the overall stiffness. The mass distribution is known but it is quite difficult to find a suitable approach for damping properties. However, damping effects are less than inertia and stiffness effects. The static analysis can be used to find the force-displacement relationships of the frame joints. Static analysis in general includes the calculation of deformations and internal forces such as bending moments, torque, bi-moments, longitudinal and shear forces. Experiments and finite element

\footnotetext{
*Corresponding author e-mail: cheefai@kutkm.edu.my
} 
analysis can determine joint rigidity. Although this framework is accounting for only a small part by weight of the entire vehicle but it exert a substantial effect on the response of the vehicle structure.

The effective design of the vehicle $\mathrm{T}$-frame will maximize the safety of the passengers and reduce the vehicle weight. It is true that the automotive industries have been working hard to reduce the vehicle weight in order to achieve better fuel efficiency and to respond to the global environmental problems. Furthermore, in improving the safety of passengers in a collision, it will be benefit to decrease the maximum load that occurs during the collision. This can reduce the level of occupant's injury and control the deformation of the structure to ensure a sufficient safe space for occupant.

Therefore, in order to reduce the vehicle body weight and at the same time maintaining satisfactory function, performance and engineering reliability, it is extremely important to establish a consistence procedure in analysing and evaluating the frame joint and to have fundamental knowledge about the behaviour of joints under loads. A point to be noted is that although the frame joints are only a small part of the entire vehicle, they exert a great influence on the structure system.

The goal of this work is to describe the designed of inner diaphragm into the automotive Tframe in several location on continuous sill member. The specimens were employed to show the effects of different location of baffles and in continuous sill member on the stiffness of $\mathrm{T}$-frame structure. A mechanical test rig was designed and manufactured in order to test the T-joint. Experimental test and finite element analysis were carried out. The results from both methods were compared and examined.

\section{RELATED WORK}

Most of the research involving joint stiffness of the automotive body structure related to thinwalled structures in which the studies are on fastened method, flexible characteristics, collapse behaviour, torsional problems and stress distributions. These studies were conducted because the frame joints give a very important affect on the vehicle response. In addition, most of the studies found that the stiffness of the frame joints greatly influenced on the overall stiffness of the vehicle body structure.

McGregor et al. [1] developed a joint design approach for adhesively bonded and spot welded aluminium automotive structures. The approach includes an allowance for joint geometric variables, manufacturing variability and complex joint loading. An important aspect in the development of the approach to minimize the detail required to model the joints in a full vehicle model. The accuracy of the approach is demonstrated on a simple structure subjected to complex loading, and the use of the approach is illustrated on a full vehicle.

Sunami et al. [2] did their analysis on the joint rigidity of the automotive body structure both in in-plane and out-of-plane bending of plane joint structures. They have made a fundamental study of the joint rigidity involving $\mathrm{T}$ or $\mathrm{L}$ shaped thin walled box beams and examining several factors that caused the rigidity to be reduced. In doing these analyses, they have used a theoretical equation; i.e. the theory of shear flow and the results confirmed by experimental values. For the in-plane study, they have concluded that the joint rigidity of box beams depends on the "release" (insufficient constrained condition) and shearing deformation and elongation of joints. From this study also they have pointed out that the analysis of fundamental behaviour of joints can be used as a step to plan structural designs. Sharman and Al-Hammoud [3] did a comprehensive study on the effect of local details on the stiffness of car body joint. Three joints between the structural members meeting the roof of a small car were tested for stiffness in the plane of the side frame. 
Niisawa et al. [4] conducted an analytical method of rigidities of thin-walled beams with spot welding joints and its application to torsion problems. In their study, they have discussed the elastic properties of the spot welding joints in the transmission of the shearing forces and developed the method based on shear flow theory in introducing the elastic properties of spot welding joints into the structural analysis of thin-walled beams. Based on this study, they found that the welding point at the middle station transmits the maximum shearing forces and the torsional rigidities do not only depend on the length of beams but also on the pitch of welding points. Vayas and Briassoulis [5] developed a method for calculating the carrying capacity and the deformation characteristics of the joints. Static and kinematic limit state models are presented which allow the ultimate strength to be determined from closed formulae.

For the finite element analysis, Shakourzadeh et al. [6] deals with the finite element formulation for the analysis of space frames. A numerical method is presented to take into account the deformation of the joint connections in linear, non-linear and stability analyses of threedimensional thin walled beam structure. Moon et al. [7] presented a joint modelling methodology where the definition and assumptions of the joint are discussed. In addition, the joint stiffness analytical model is proposed using static load test results and also presented the sensitivity analysis method and a joint stiffness-updating algorithm. To verify these methods, the FE analysis results of a half size structural model of an automobile with rigid joints and rotational spring joints are compared with experimental analysis results. Farooque et al. [8] proposed the finite element formulation to incorporates rectangular plate and edge boundary spring elements. The model is then used to determine the punching shear and rotational stiffness of both double chord $\mathrm{T}$-joints and single chord $\mathrm{T}$-joints, thus demonstrating its versatility. The numerical values obtained are in good agreement with the experimental results available in the literature.

\section{FUNDAMENTAL ASPECT OF THE SPECIMEN}

The cold rolled mild steel sheet was used to construct the specimens. It consisted of five components that are the base plate, inner diaphragm (baffles), vertical member, horizontal member (sill) and the jointing member. Once constructed, it formed a T-joint member with 75 $\mathrm{mm}$ corner radius at the jointing area and with closed hat section members and spot welded along its flanges.

The base plate was a planar sheet with $1.2 \mathrm{~mm}$ thickness in the form of T-shape with $55 \mathrm{~mm}$ corner radius. The horizontal member is an open hat section with $20 \mathrm{~mm}$ flanges over the complete length and having the same thickness as the base plate. It is connected to the base plate by means of spot welds at the pitch distance of $50 \mathrm{~mm}$. Before these two components are connected, the inner diaphragms are connected to their particular locations in the horizontal member by means of three spot welds at two equal pitches all the way round except the one that faces the base plate. This has been plug welded at two equal distances with the base plate. The purpose of having these holes and extension length is to build a box of cement block at each end so that it can be regarded as fixed ends.

The vertical member is connected to the base plate by means of spot welds. This assembly is connected to a connecting plate with dimensions of $180 \times 180 \times 10 \mathrm{~mm}$ at the top part of the assembly by means of $\mathrm{CO}_{2}$ arc welding. The purpose of having the connecting plate is ensuring that the vertical member will move as one entity when loads are applied.

The jointing member connects the base plate, vertical/horizontal member by means of spot welds, fillet welds, plug welds and $\mathrm{CO}_{2}$ arc welds. Plug welds were used in any area where spot welding electrodes were not accessible due to the shape of the T-joint. Although the jointing member was designed as one piece, in actual case it is made from three pieces of steel which are joined by one $\mathrm{CO}_{2}$ arc welding operation due to the lack of production tools. In production 
cars the hat section of the sill and ' $\mathrm{B}$ ' post are formed as one pressing. The specimen construction attempted to simulate this without the facilities of press tools.

\subsection{Type of specimen}

In this work, a specimen has been constructed with three examples where its using a continuous sill member. The inner diaphragms have been located in-line with the sides of Bpillar (AM1), at the weld line (AM2) and at the outside of the weld line (AM3). The information about the specimen as shown in Table 1. Figure 1 shows the design of the specimen.

Table 1. Specimen: continuous horizontal member.

\begin{tabular}{lccc}
\hline Specimen's Identity & AM1 & AM2 & AM3 \\
\hline Location of Baffles (Left and Right) & $160 \mathrm{~mm}$ & $272 \mathrm{~mm}$ & $40 \mathrm{~mm}$ \\
\hline
\end{tabular}

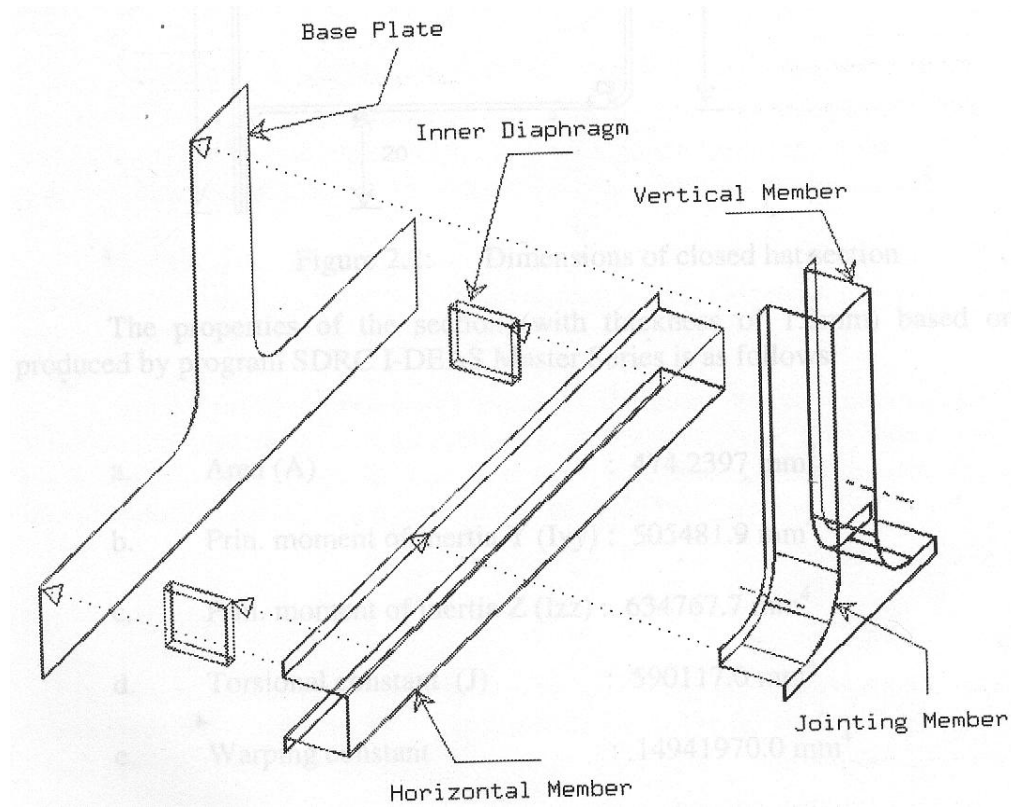

Fig. 1: Parts of specimen.

\subsection{Experimental testing}

The In-plane bending case was considered in the experimental testing. The load applied at the top part of the vertical member and in parallel with the horizontal member (Figs. 2, 3 and 4). The total displacement can be written as:

$$
\delta_{\mathrm{t}}=\delta_{\mathrm{VW}}+\delta_{\mathrm{HW}}+\delta_{\mathrm{HM}}
$$

Based on these rotational assumptions, therefore through experimental test or finite element analysis, the stiffness of the joint can be easily obtained. Where through experimental test, the total displacement can be obtained, while the displacement of each member due to deformation of a beam can be calculated using beam theory or finite element analysis. In addition, the 
displacement at the loading point can be transformed into function, which includes the angular stiffness of the joint.

To conduct the in-plane experimental testing, a mechanical test rig was designed and manufactured. The test rig was built to be flexible and accurate. The test rig also equipped with tensile gauge, turnbuckles, a clamping set, Dexion frame and dial gauges.

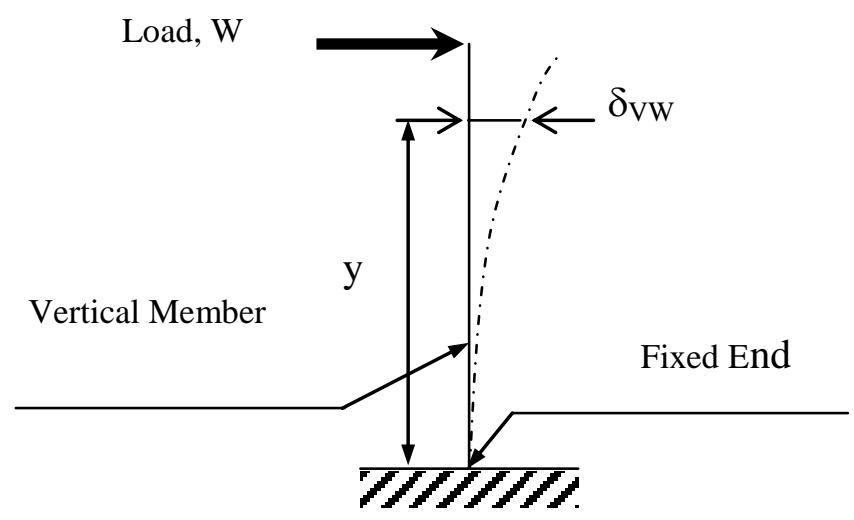

Fig. 2: Vertical member as a cantilever.

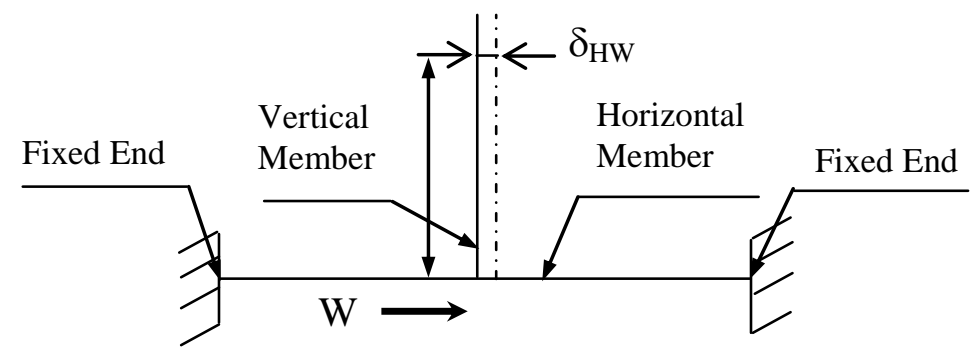

Fig. 3: Horizontal member subjected to axial load, W.

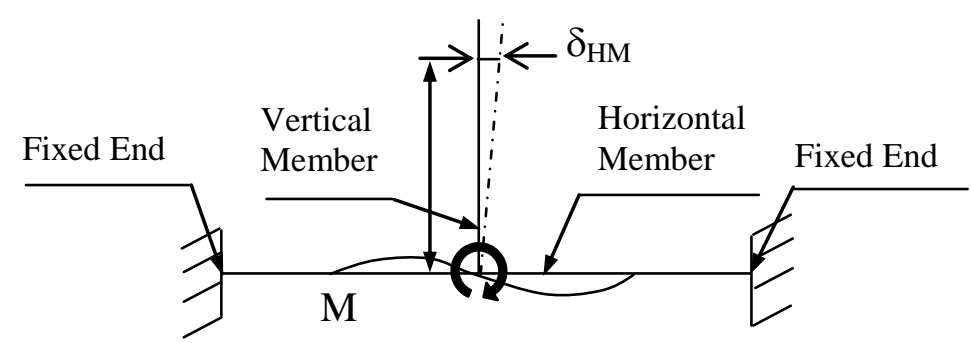

Fig. 4: Horizontal member subjected to bending moment.

\section{EXPERIMENTAL TEST RESULTS}

For the in-plane bending, 4 points were measured at the specimen. This points were represented 
by W, X, Y and Z (refer to Fig. 5). Figure 6 shows the in-plane bending experiment on the test rig.

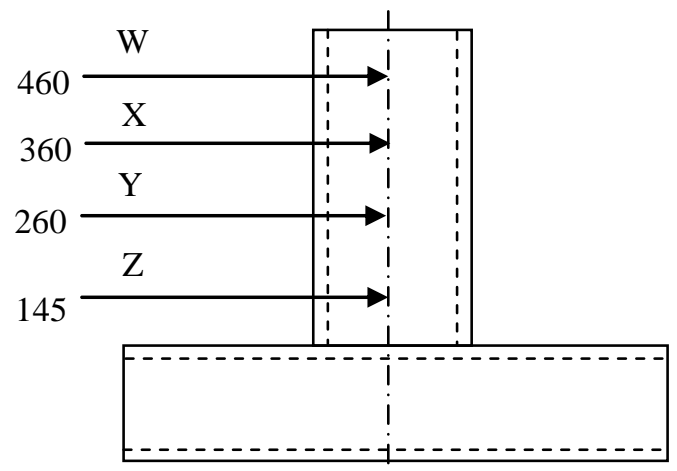

Fig. 5: Location of points for experimental testing. (All dimensions in $\mathrm{mm}$ ).

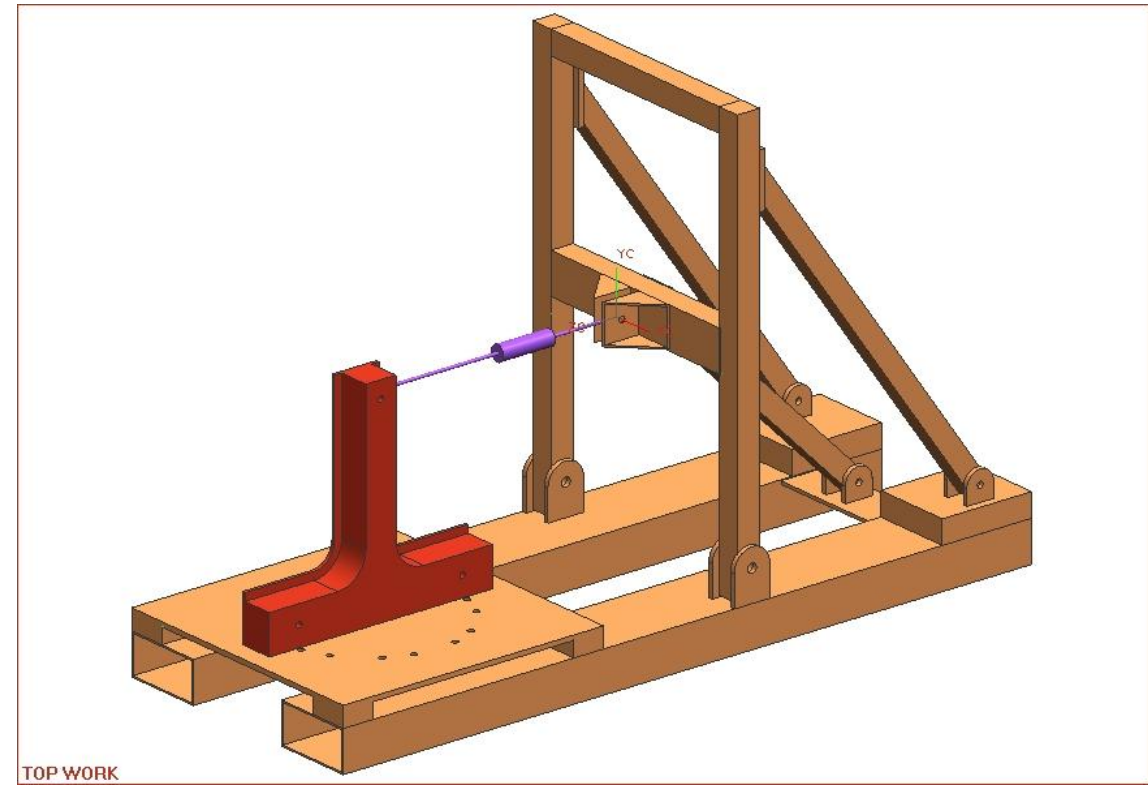

Fig. 6: The in-plane bending experiment on the test rig.

\subsection{In-plane bending test result for specimen AM1}

Specimen AM1 is a continuous sill member with the baffles located at the weld line i.e. $160 \mathrm{~mm}$ left and right from the centreline of the T-joint. The linear of displacement with load occurred at point $\mathrm{W}, \mathrm{X}, \mathrm{Y}$ and $\mathrm{Z}$ is shown in Graph 1.

\subsection{In-Plane Bending Test Result for Specimen AM2}

This specimen is a continuous sill member with the baffles located at the outside of the weld lines i.e. $272 \mathrm{~mm}$ left and right from the centreline. The experimental results for AM2 as shown in Graph 2. Graph 2 show the deflection versus distance (location), where it is constructed based on maximum load applied. 
Graph 1. Deflection vs. load (Linearity Displacement).

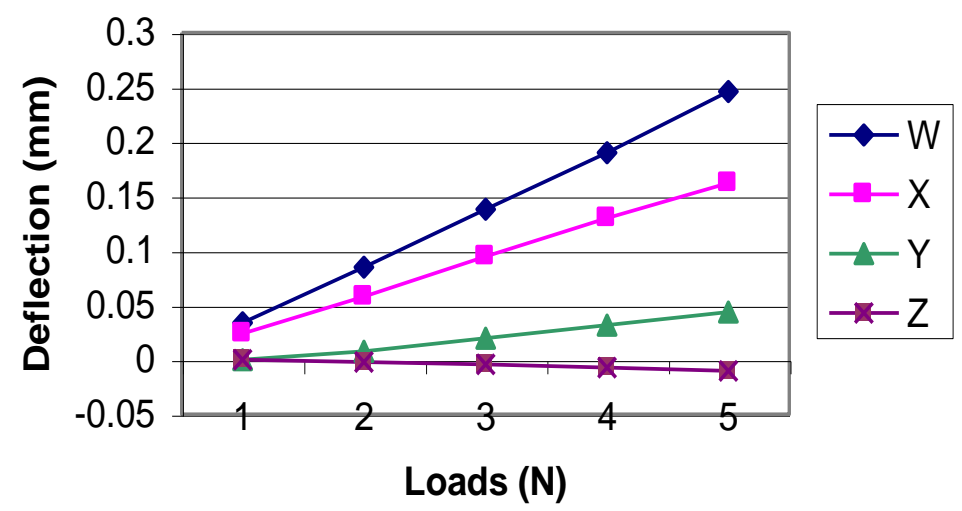

Graph 2. Distance vs. Deflection (AM2).

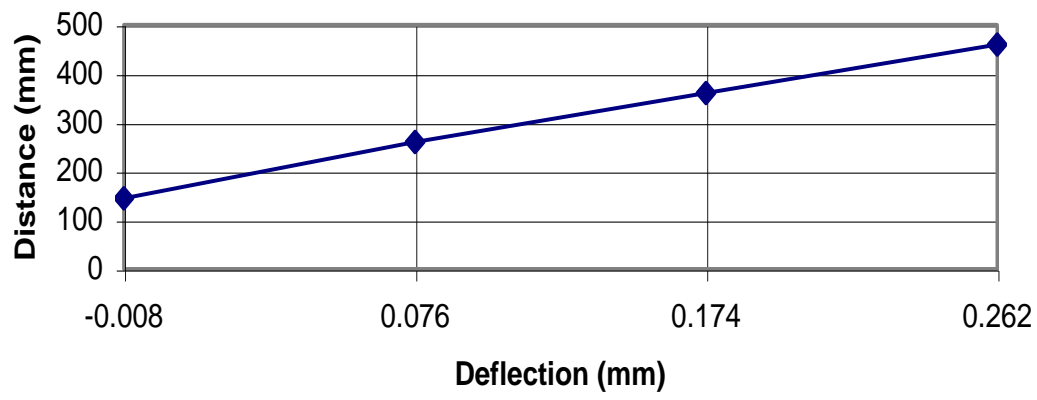

\subsection{In-plane bending test result for specimen AM3}

The specimen is a continuous sill member with the baffles located in-line with the vertical member, i.e. $40 \mathrm{~mm}$ left and right from the centerline. He experimental results for AM2 as shown in Graph 3. The graph of deflection versus distance (location) is constructed based on the maximum load applied. Graph 3 also shows that negative displacement existed at the joint region, i.e. point $\mathrm{Z}$. This is the bowing effect due to compression.

Graph 3. Distance vs Deflection (AM3)

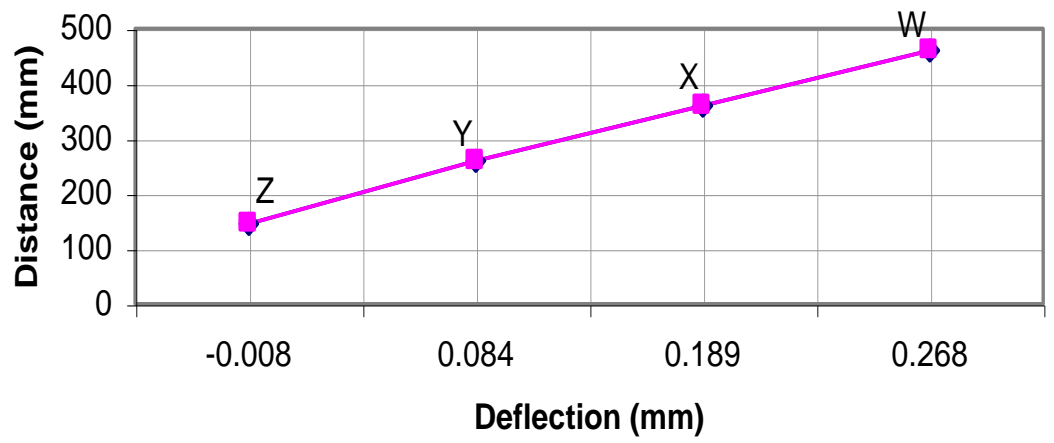




\subsection{Deflection of vertical member and joint region of continuous sill member}

The results obtained based on $900 \mathrm{~N}$ longitudinal load to specimen Type 1 has been tabulated as shown in Table 2 and Graph 4.

Table 2: Deflection of vertical member and joint region Type 1.

\begin{tabular}{lllll}
\hline Location & W & X & Y & Z \\
\hline AM1 & 0.246 & 0.162 & 0.044 & -0.010 \\
AM2 & 0.262 & 0.174 & 0.076 & -0.008 \\
AM3 & 0.268 & 0.189 & 0.084 & -0.008 \\
\hline
\end{tabular}

Graph 4. Deflection of vertical member and joint region of continuous sill member (Unit: mm).

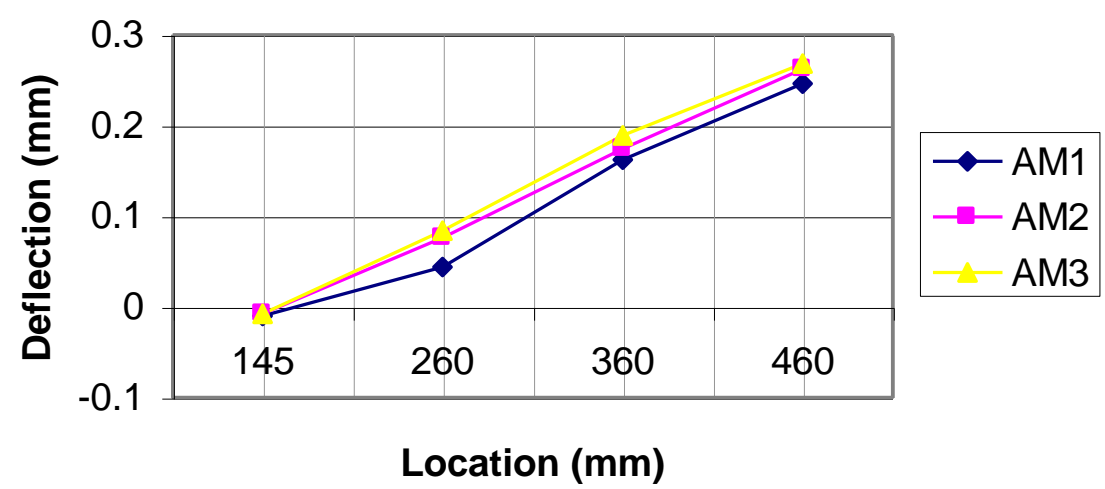

Based on Table 2 And Graph 4, the following are the pre-conclusion that can be made:

a. Location of baffles on a continuous sill member does not give any major influence on the in-plane bending case. However, among these specimens, the specimen with baffles located at the weld line is stiffer than the baffles located with the side of B-pillar.

b. No matchbox effect occurred in these types of specimens.

\section{FINITE ELEMENT ANALYSIS}

The modeling of the specimen has been carried out in order to represent the actual joints of a vehicle and comparing its results with the results obtained from experimental testing. All of the finite element (FE) consisted of four main parts i.e. base plate, vertical member, horizontal member and inner diaphragm (baffles). The model was created using square corner (i.e. no corner radii) in order to reduce the process time.

The model were constructed using thin shell element without considering the solid modeling since the thickness of the plate is only $1.2 \mathrm{~mm}$ mapped meshed were used throughout the construction of the model in order to get better accuracy and moreover the model did not have any irregular shape. A four nodded simple rectangular element was used for mapped the meshing. 
The top surface of the vertical member were constraint using rigid element so that it can moved as a unit when loads were applied.The base plate and the vertical member/horizontal member were connected by means of beam element (representing spot welds) at the pitch distance of $50 \mathrm{~mm}$. The inner diaphragm are connected to their particular location in the horizontal member by means of three beam elements at two equal pitches all the way round. Both ends of the horizontal member were fully restrained from any degree of freedom, which represent as fixed ends. Two forces were located along the edge (on the nodes) of the top surface of the vertical member (i.e. facing the direction of the force). 900 $\mathrm{N}$ force was used for in-plane bending case.

\subsection{FE results}

For the FE analysis, tolerance of $\pm 5 \mathrm{~mm}$ has been given for the locations of the measurement.

\subsubsection{Model AM1}

The results obtained from the FE analysis are shown in Graph 5. The deformed model is shown Fig. 6. It can be seen that the joint region of the vertical member and the center region of the horizontal member were largely deformed.

Graph 5. Deflection versus distance (AM1)
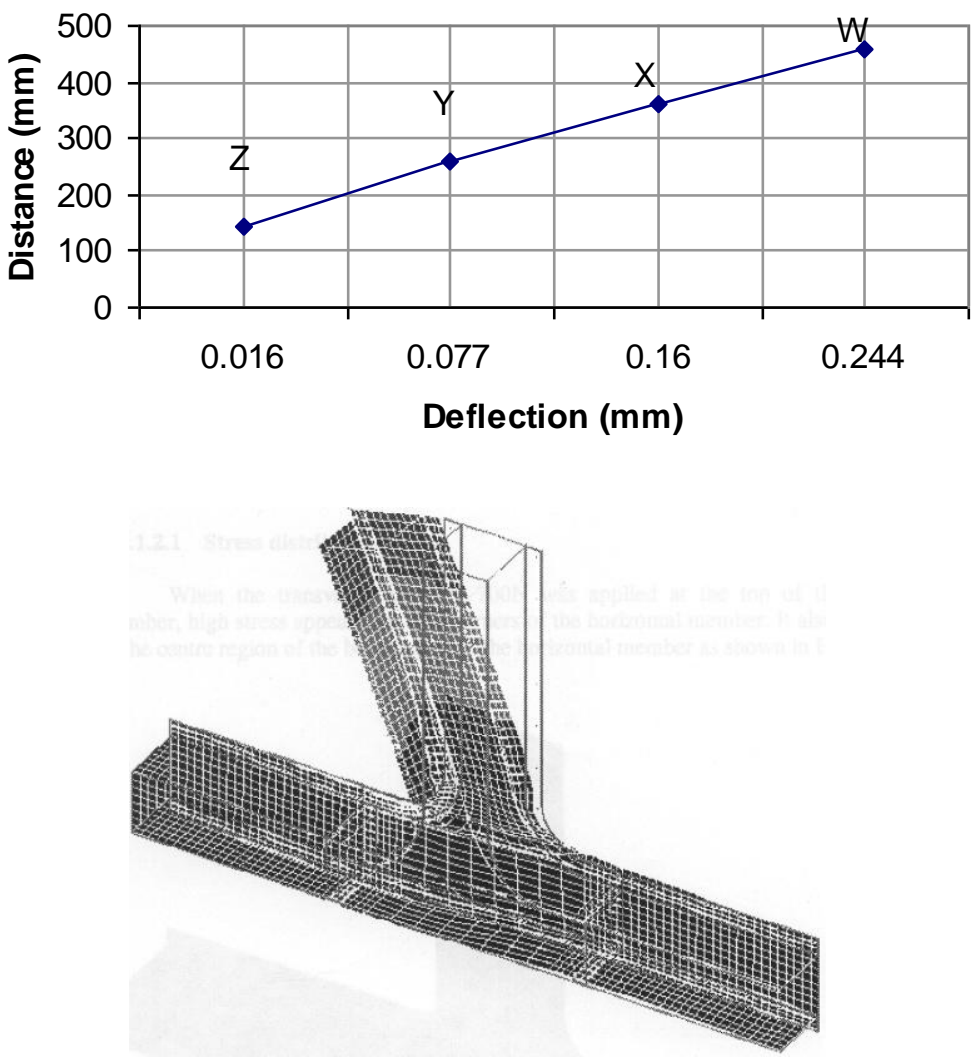

Fig. 6: Stress distribution for model AM1. 


\subsubsection{Model AM2}

The stress distribution appeared in model AM2 is quite similar to AM1 when longitudinal of $900 \mathrm{~N}$ was applied at the top of the vertical member. The results as shown in Graph 6, the graph shows no negative displacement occurred and therefore no occurrence of local bending at the particular point of measurement. High stress appeared to be along the flanges at the corner radii region.

Graph 6. Deflection versus distance (AM2).

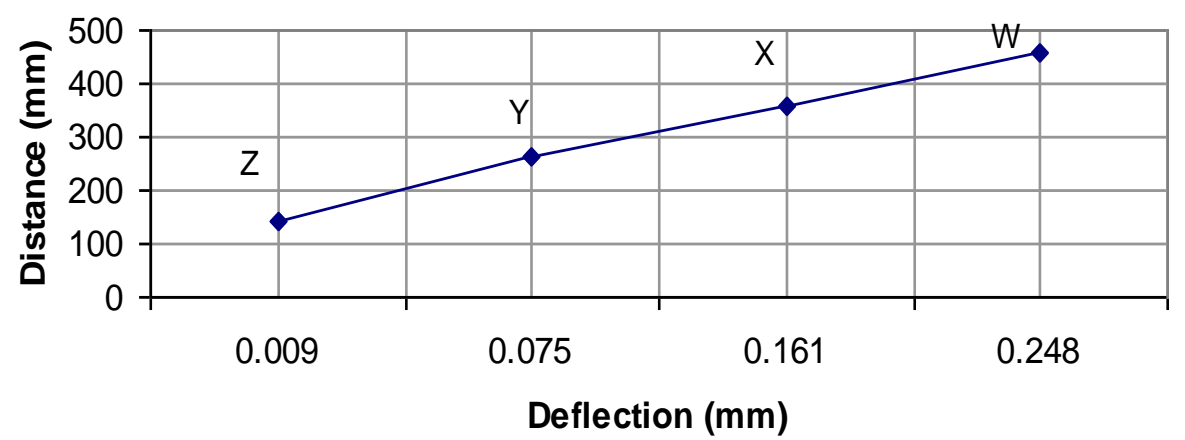

\subsubsection{Model AM3}

The results obtained from FE analysis for AM3 are shown in Graph 7. The stress for AM3 is concentrated along the flanges in the corner radii region. The model AM3 have baffles located in-line with the vertical line, therefore it prevents the model from being largely deformed at the center region. However, it starts deformed immediately after the right baffle.

Graph 7. Deflection versus distance (AM3).

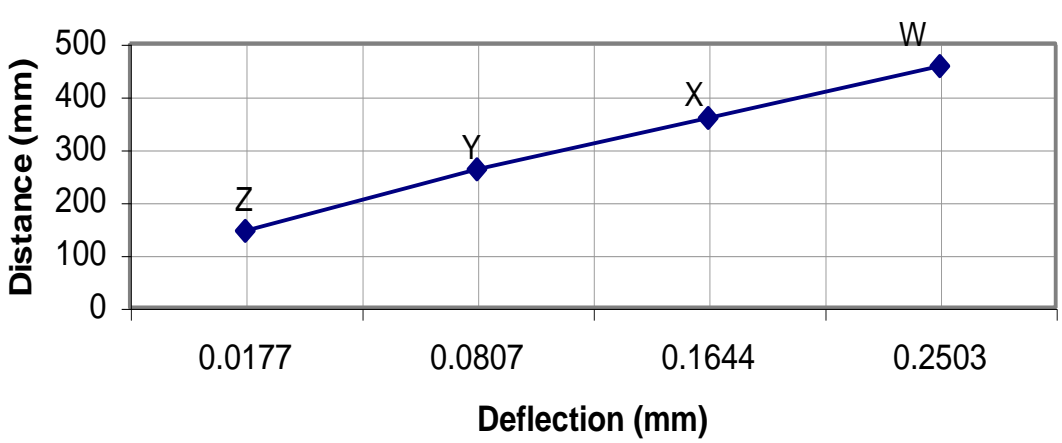

\subsection{Deflection of vertical member and joint region of continuous sill member}

The results obtained based on $900 \mathrm{~N}$ longitudinal load applied to T-flames in FE analysis have been tabulated in Table 3 and Graph 8.

Based on Table 3 and Graph 8, the following are the pre-conclusion that can be drawn.

a. Model AM1 is stiffer than the other two models. However as the locations of measurement is nearer to the joint area, model AM2 shows that it is the stiffest among the models.

b. No 'match box' effect occurred. 
Table 3: Deflection of vertical member and joint region (Unit: $\mathrm{mm}$ ).

\begin{tabular}{lllll}
\hline Location & W & $\mathbf{X}$ & $\mathbf{Y}$ & $\mathbf{Z}$ \\
\hline AM1 & 0.244 & 0.160 & 0.077 & 0.016 \\
AM2 & 0.248 & 0.161 & 0.075 & 0.009 \\
AM3 & 0.250 & 0.164 & 0.081 & 0.018 \\
\hline
\end{tabular}

Graph 8. Deflection of vertical member and joint region of continuous sill member.

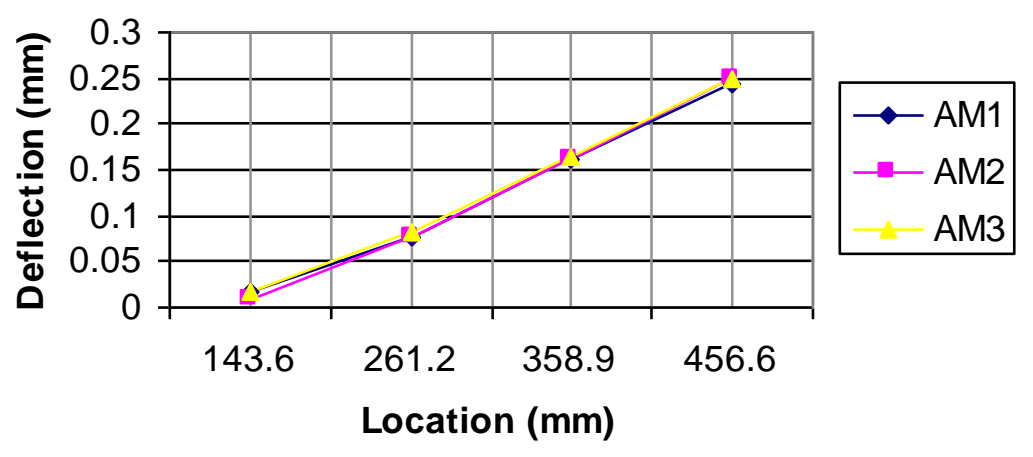

\section{CONCLUSION AND DISCUSSION}

The results obtained from experimental analysis and finite element analysis has been tabulated in Table 4.

Table 4: Displacement of vertical member due to longitudinal load of $900 \mathrm{~N}$.

\begin{tabular}{ccccccc}
\hline \multirow{2}{*}{ Location } & \multicolumn{3}{c}{ Experimental test } & \multicolumn{3}{c}{ Finite element analysis } \\
\cline { 2 - 7 } & AM1 & AM2 & AM3 & AM1 & AM2 & AM3 \\
\hline W & 0.246 & 0.262 & 0.268 & 0.244 & 0.248 & 0.250 \\
& & & & $(99 \%)$ & $(95 \%)$ & $(93 \%)$ \\
X & 0.162 & 0.174 & 0.189 & 0.160 & 0.161 & 0.164 \\
Y & 0.044 & 0.076 & 0.084 & 0.077 & 0.075 & 0.081 \\
Z & -0.010 & -0.008 & -0.008 & 0.016 & 0.009 & 0.018 \\
\hline
\end{tabular}

From Table 4, it can be seen that the results obtained from FE analysis gave deflection within the range of $93 \%$ to $99 \%$ of the experimental test. There are differences of the results for both analyses especially at point $Z$. From FE analysis, there are no negative displacement occurred at point $Z$. These results seem to be contradicted with the results obtained from the experiment test but the reason can be found in the quality of the specimens. The result shows that specimen AM1 is stiffest model and AM2 is stiffer than AM3.

Based on the results obtained from the experimental work, location of baffles for the specimens 
do not gives any major influences for in-plane bending case due to the shape and direction baffles are not suitable. However, the specimen with baffles located at the weld line is stiffer than the other specimens. The future work will carry out for out-of-plane bending as well as the non-continuous sill member.

\section{ACKNOWLEDGMENTS}

The author gratefully acknowledges the financial support from Kolej Universiti Teknikal Kebangsaan Malaysia.

\section{REFERENCES}

1. McGregor, I.J., Nardini, D., Gao, Y., and Meadows, D.J. (1992), Development of A Joint Design Approach for Aluminium Automotive Structures, SAE Technical Paper Series, 922112, pp. 1-13.

2. Sunami, Y., Yugawai, T., and Yoshida, Y. (1998), Analysis of joint rigidity in plane bending of plane-joint, JSAE Review, 9(2).

3. Sharman, P.W. and Al-Hammoud, A. (1987), The effect of local details on the stiffness of car body joints, International Journal of Vehicle Design, 8(4/5/6), pp. 526-537.

4. Niisawa, J., Tomioka, N., and W. Yi. (1984), Analytical method of rigidities of thin-walled beams with spot welding joints and its application to torsion problems, JSAE Review, 11(3).

5. Vayas, I. and Briassoulis, D. (1993), Behavior of Thin-Walled Steel Frame Joints, Journal of Constructional Steel Research, 24(2), pp. 105-119.

6. Shakourzadeh, H., Guo, Y.O., and Batoz, J.L. (1999), Modeling of Connections in the Analyses of Thin-Walled Space Frames, Computers and Structures, 71(4), pp. 423-433.

7. Moon, Y.M., Lee, H., and Park, Y.P. (1999), Development of An Automotive Joint Model Using An Analytically Based Formulation, Journal of Sound and Vibration, 220(4), pp. 625-640.

8. Mirza, F.A., Shehata, A.A., and Korol, R.M. (1982), Modeling of double chord rectangular hollow section T-joints by finite element method, Computers \& Structures, 15(2), pp. 123129. 